\title{
$\mathrm{PH} 101_{\text {cosate }}$
}

a debate Hacia una nueva institucionalidad cultural. Modelos emergentes de gestión...

| coordina Jesús Carrillo Castillo

\section{Los horizontes de la institución cultural ante la Covid 19}

\author{
Jesús Carrillo Castillo | Dpto. Historia y Teoría del Arte, Universidad Autónoma de Madrid
}

URL de la contribución <www.iaph.es/revistaph/index.php/revistaph/article/view/4766>

El debate de este número de revista $\mathrm{PH}$, dedicado a reflexionar sobre los horizontes de la institucionalidad cultural, ha coincidido con un periodo de excepcionalidad: el generado por la Covid 19, que ha agudizado las patologías que diagnostican buena parte de los textos que respondieron a la convocatoria, a la vez que marca con claridad el sentido en el que sería necesario intervenir hacia el futuro. El efecto inmediato ha sido catastrófico: clausura de museos y centros de arte e interrupción del trabajo de los creadores y trabajadores culturales por la cancelación de las actividades de las que derivan sus ingresos. A medio plazo la situación no se presenta en absoluto halagüeña: el hundimiento de la industria turística y del ocio a la que muchas de las infraestructuras y programaciones habían unido su destino; la imposible materialización del público tal y como lo hemos entendido hasta hoy debido a las restricciones derivadas de la "distancia social" y, por último, el desplazamiento de los recursos del Estado a áreas prioritarias para el sostenimiento de la vida, entre las que no se reconoce a la cultura. Sobre esto último volveremos al final del texto.

Se ha hecho evidente la necesidad de un giro urgente en el modelo de institución que afecte a su relación con el medio, a su concepción de los públicos y a su vinculación con la vida en general. Los textos aquí reunidos nos dan algunas claves de la dirección a seguir. Los principios de sostenibilidad y de relación ecosistémica con el tejido social, en conjunción con una horizontalización y democratización de la gobernanza, han cobrado de repente carácter de imperiosa necesidad. Más allá de ofrecer una alternativa virtuosa a organismos anquilosados en sus estructuras y mercantilistas en sus operaciones, estos principios aparecen como el único camino para la supervivencia de la institución cultural en el impasse actual.

Como se desprende de los argumentos y de las referencias manejadas por nuestros autores, en las dos últimas décadas ha ido madurando en nuestro entorno un corpus muy sofisticado tanto de pensamiento como de prácticas dirigidas a la transformación de la institución cultural que, muy a menudo, ha sido elaborado en el interior o en estrecho diálogo con esa misma institución. También constatamos en la lectura de algunos de estos textos una sensación de agotamiento y de desánimo acumulada tras años de ímprobo esfuerzo y de expectativas incumplidas. Ello viene acompañado de un justificado escepticismo tanto respecto a la capacidad de quienes rigen las instituciones o diseñan las políticas culturales de aprender de dichos saberes y de dichas experiencias, como respecto a su voluntad de implementar cambios estructurales.

Es característico de la formación de nuestro entramado institucional el que viniera acompañado desde sus inicios por la formulación de alternativas críticas. Tal vez ello se deba a la pervivencia de aspiraciones insatisfechas por los consensos de la Transición en una esfera cultural que había adquirido sus señas de identidad en la lucha contra el régimen franquista. Estos círculos han tendido a considerar la institución como un proyecto abierto de profundización democrática y no como un dispositivo destinado a la dotación de servicios, o a la exhibición y legitimación del poder. El conocido texto "Síndrome de mayoría absoluta", firmado en 1989 por Mar Villaespesa, da buena cuenta de una latente conciencia crítica presta a denunciar los comportamientos de una escena cultural espuria (VILLAESPESA, 1989).

Desde mediados los 90, en pleno ciclo de inauguraciones de grandes infraestructuras culturales promovidas desde las distintas administraciones del Estado, observamos la pugna por un espacio cultural de otra naturaleza; uno que diera cabida a la iniciativa de la sociedad civil, tanto de los creadores como de los públicos. En 1994 nace la Red Arte, que intentó construir un frente común de la escena independiente que comenzaba, por 


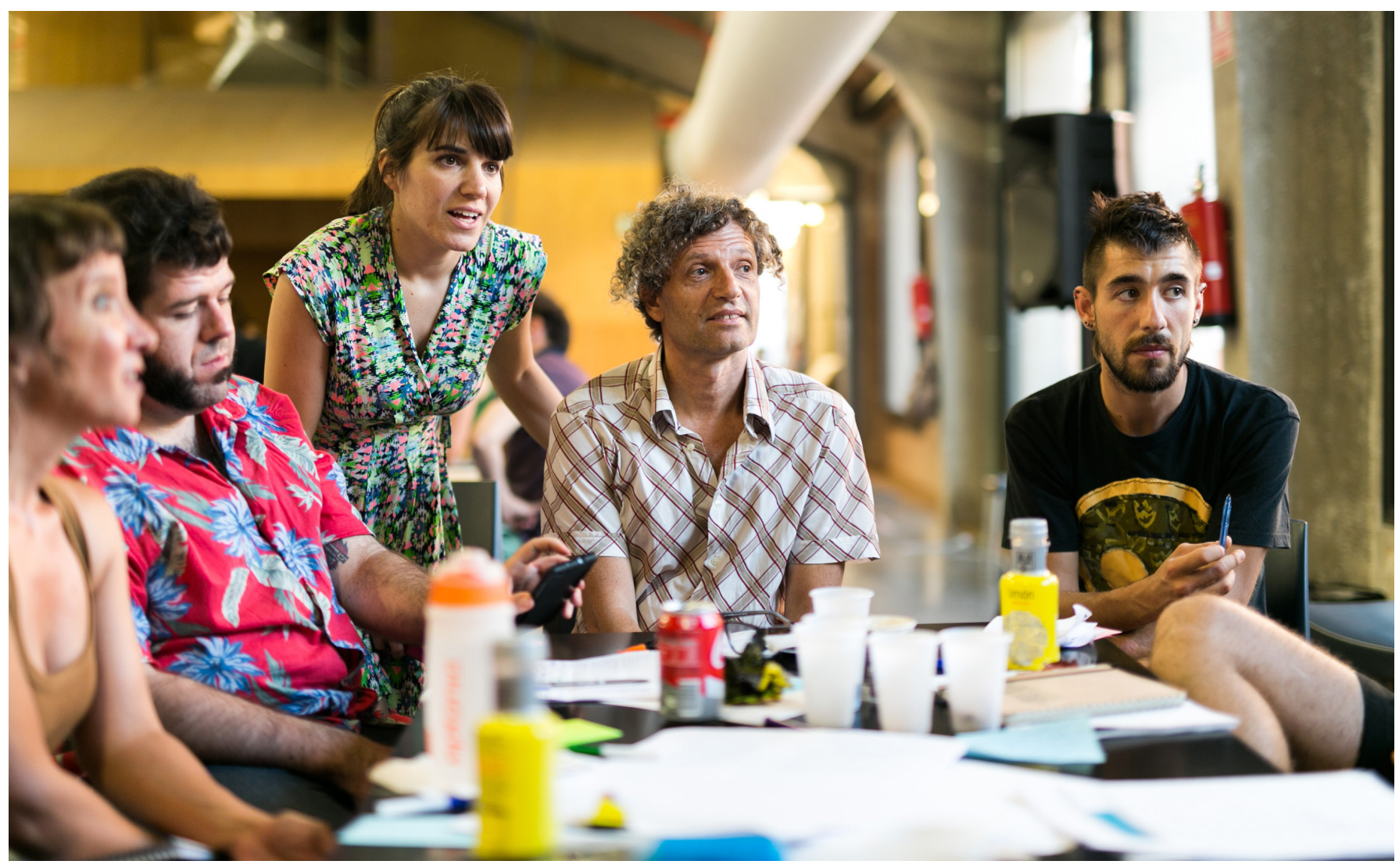

Los Laboratorios 3: Acercamiento al ecosistema cultural institucional de Madrid | foto Medialab Prado

entonces, a desplegarse por todo el territorio. 1997 es el año de la creación de Hangar por la asociación catalana de artistas visuales, un espacio auto-gestionado en el que acceder a recursos para la creación al margen de la dependencia institucional. Simultáneamente nacía en Bilbao Consonni, una empresa colectiva con la vocación de generar las condiciones para una producción artística "otra", vinculada a los procesos y a la relación con el contexto social más que al mercado. En 1998 se constituye Zemos 98 en las cercanías de Sevilla, a partir de la voluntad de un grupo de jóvenes de dotarse de una agencia cultural adecuada a las condiciones de producción, distribución y demanda contemporáneas ante una institución que consideraban ineficaz y obsoleta.

El volumen Servicio público, editado ese mismo año por Jorge Ribalta (RIBALTA, 1998), deja constancia de la intensidad del debate y de la necesidad de reconfigurar la institución cultural desde parámetros que dieran cuenta de estas demandas. La conversación con Marcelo Expósito incluida en el libro enumera los principios que, según este último deberían guiar unas políticas culturales de nuevo cuño: la apertura y desburocratización de la institución y el diálogo abierto con los nuevos sujetos políticos que estaban articulándose lejos de los cenáculos del mundo del arte: en la "sociedad civil alternativa" que estaba emergiendo desde lo local al ámbito global. El traslado subsiguiente de Jorge Ribalta al Macba como responsable de actividades públicas introduciría algunos de estos idearios en el interior del museo alumbrando la posibilidad de una transformación institucional desde adentro. Este movimiento iba a generar una profunda perturbación en el debate, que reverbera aún hoy, al identificarse el museo como sujeto y objeto 
a debate Hacia una nueva institucionalidad cultural. Modelos emergentes de gestión...

| coordina Jesús Carrillo Castillo

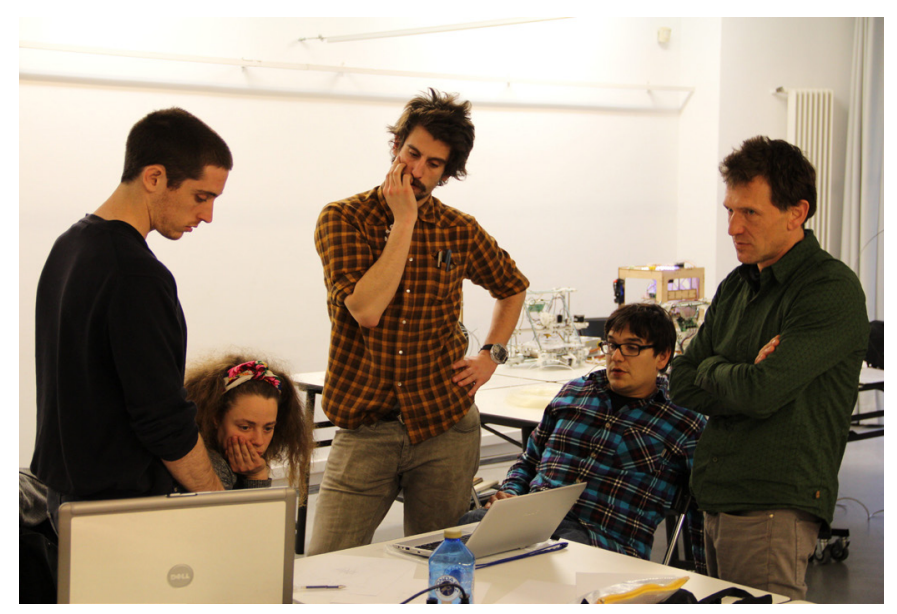

Jornadas Tresnak::Tools organizadas por Arteleku, Tabakalera, KIMU, con la colaboración de la E.T.S. de Arquitectura de la EHU, San Sebastián y MedialabPrado | foto Medialab-Prado

simultáneo de crítica, con el riesgo latente de desplazar o subsumir a los protagonistas por antonomasia del antagonismo.

Estos cambios y perturbaciones no solo implicaron al Macba. Por esa misma época se pone en marcha el programa de "proyectos asociados" de Arteleku. Dependiente de la Diputación de Guipúzcoa, Arteleku había nacido en 1987 como una anomalía respecto al patrón de colección más sala de exposiciones que iba a proliferar en España durante la década siguiente. Concebido originalmente como un centro de formación y producción por y para los artistas, diez años después de su fundación iba a desplazar el eje del individuo creador para dar protagonismo a un sujeto difuso, colectivo e implicado políticamente, más interesado en analizar y debatir críticamente las condiciones del cambiante mundo contemporáneo que en producir objetos de arte. En Arteleku la biblioteca y el espacio de discusión iban a desplazar al taller de artista.

La primera década de los 2000 iba a ser escenario de la tensión entre dos concepciones de la cultural aparentemente antagónicas. Por un lado, un modelo neoliberal de institución, crecientemente privatizada y externalizada en sus funciones, enfocada a la instrumentalización de

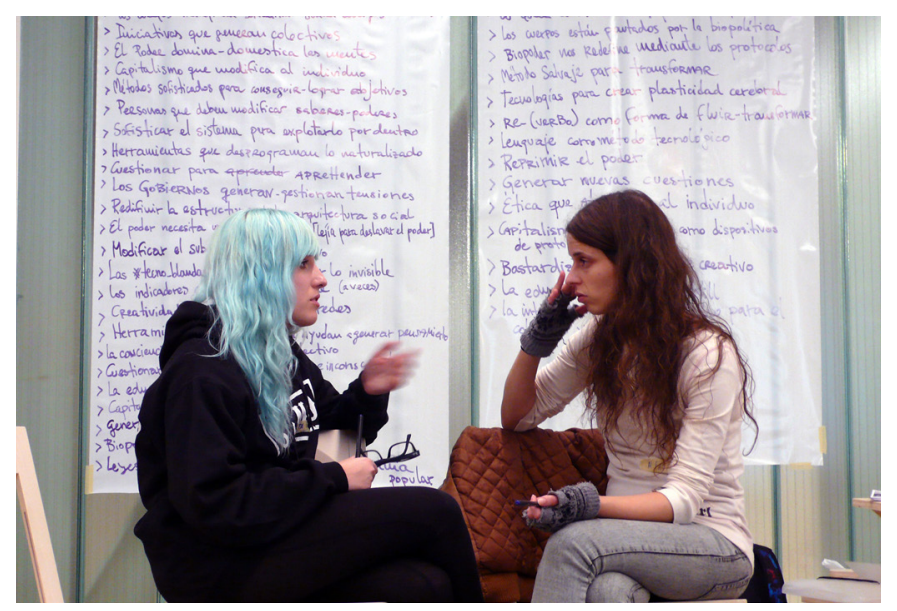

3. a sesión para la creación de una ontología sobre \#tecno_blandas en Hirikilabs (Tabakalera, Donostia), el viernes 27 de noviembre de 2015 | foto ColaBoraBora (Saioa Olmo)

la cultura y del arte para atraer la inversión inmobiliaria y la industria turística. Por otro lado, un modelo autonomista y autogestionario defendido por activistas, agentes independientes y trabajadores culturales, en ocasiones amparados por esas mismas instituciones, que identificaban el arte y la cultura como catalizadores de procesos de transformación y de empoderamiento social.

Las nociones de clase y ciudad creativas enunciadas por Richard Florida (FLORIDA, 2002), recibidas con entusiasmo por los diseñadores de políticas culturales de las distintas administraciones públicas, iban a introducir un ingrediente de complejidad en este escenario haciendo que, en ocasiones, ambos polos se confundieran. En sus propuestas confluían la noción neoliberal de la cultura como recurso para ser explotado, que agudamente analizara George Yudice (YÚDICE, 2002), con el énfasis en una ciudadanía creativa y participativa que sería el motor de dicho proceso de generación de riqueza. La fábrica industrial vaciada por el nuevo sistema productivo iba a dejar paso en nuestras ciudades a las fábricas de la cultura: Tabakalera Donosti, Matadero y Casa Encendida en Madrid, C3A Córdoba, y muchas otras iniciativas de centros de cultura urbana que competirían con el modelo "museo" dominante en la década anterior (CARRILLO, 2008). 


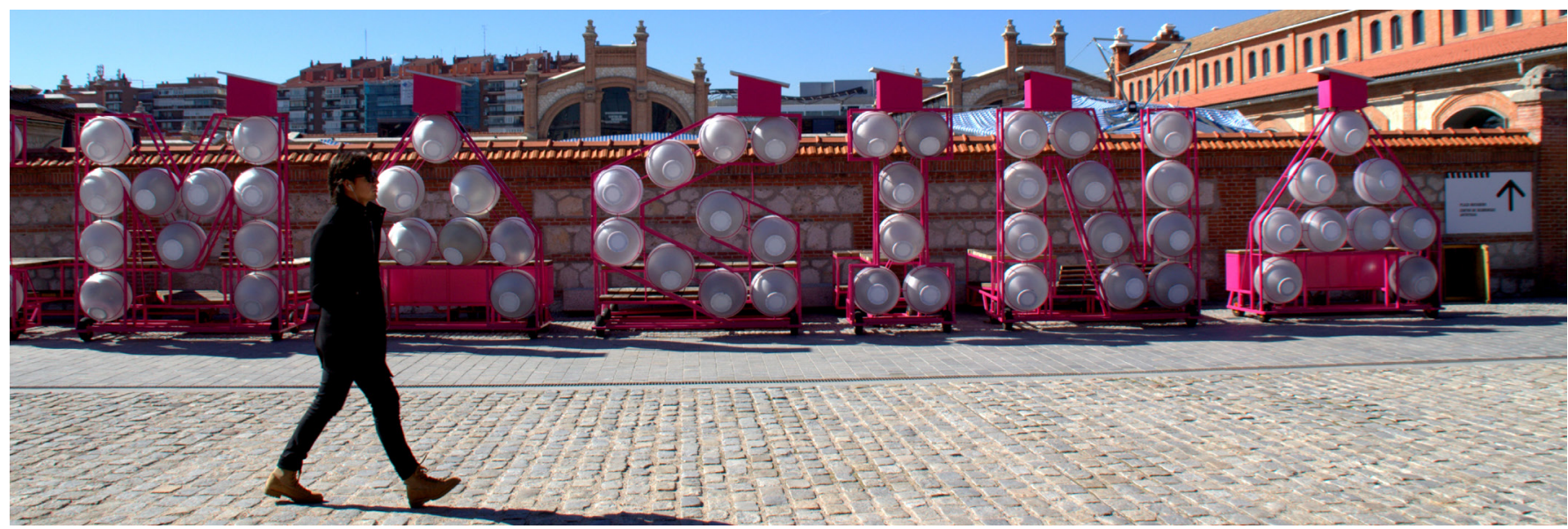

Imagina Madrid, el programa de arte público y comunitario impulsado por el Área de Cultura del Ayuntamiento de Madrid y dirigido por Intermediæ-Matadero, para intervenir en nueve espacios en desuso de la ciudad. Exposición en la que se detalla la idea de cada uno de los proyectos en la Nave 16 de Matadero | foto manuel m. v.

Este modelo productivista iba a encontrar una nueva generación de críticos, artistas y activistas que defendían una relación radicalmente distinta entre cultura y ciudad. La publicación en 2001 del volumen colectivo Modos de hacer (BLANCO; CARRILLO; CLARAMONTE, 2001) servía de bisagra teórica para abrir el ensimismado mundo del arte hacia el espacio público y sus luchas, fundamentalmente la pugna por espacio urbano que, por entonces, estaba siendo asediado por los proyectos gentrificadores del capital y las administraciones públicas. Las propuestas de la Red de Lavapiés, que culminarían en 2004 con la propuesta de transformación de la Tabacalera madrileña en un centro cultural autogestionado por el vecindario y la exitosa colaboración entre artistas y vecinos en defensa del Cabanyal valenciano, dan cuenta de la colaboración entre arte y reivindicación política del derecho a la ciudad en la formulación de alternativas frente a los violentos embates del neoliberalismo (CARRILLO, 2018).

La crisis financiera de 2008 iba a hacer tambalearse el castillo de naipes de un sistema cultural íntimamente dependiente de la burbuja especulativa, no solo en sus fundamentos económicos, sino también en los ideológicos y estéticos, al apoyarse en una versión del arte y de sus espacios como excitantes reclamos al consumo y a la entusiasta adhesión al sistema. Muchos de los proyectos de infraestructura cultural de la década quedaron paralizados o inconclusos, y los supervivientes vieron sus recursos gravemente menguados. A río revuelto y con un gran malestar social de fondo iban a producirse reacciones de distinto signo, derivadas de los procesos previamente descritos y de las que hoy somos herederos directos. En vez de favorecer la desregulación y los procesos colaborativos, tal como se venía reivindicando desde los 90, la administración endureció los procedimientos de control del gasto mediante un marco jurídico restrictivo que pretendía garantizar la austeridad desde 2012 y que se vería confirmado por la nueva ley de contratos públicos de 2017. Este reforzamiento de la supervisión burocrática sería paradójicamente compatible con el debilitamiento de la potencia y la autonomía de la institución cultural abocada a la externalización y privatización de sus funciones, ahora identificadas plenamente como "servicios" subcontratables. El resultado sería un estrangulamiento de las capacidades proyectivas y ejecutivas de la institución y la precarización e inestabilidad del trabajo cultural en su conjunto, particularmente el dedicado a la mediación y la educación.

La pinza burocrático-neoliberal derivada del traumático impasse de la austeridad se iba a encontrar con un 
a debate Hacia una nueva institucionalidad cultural. Modelos emergentes de gestión...

| coordina Jesús Carrillo Castillo

reforzado frente crítico capaz de elaborar desde dentro y desde afuera de la institución análisis y propuestas acerca de otra cultura y otra institución posibles. Los debates promovidos por el colectivo Yproductions en Barcelona (YPRODUCTIONS, 2007), del que Jaron Rowan era partícipe, y por el Observatorio Metropolitano en Madrid (OBSERVATORIO METROPOLITANO, 2007), entre otros, se aproximaban a la cultura desde dos ejes clave: el análisis de las condiciones de producción y trabajo del capitalismo cognitivo y la crítica a la dislocación de la ciudad derivada del urbanismo neoliberal. Por su parte, un colectivo de investigación y pensamiento crítico, la Universidad Nómada, activo desde comienzos de la década, identificaba la coyuntura de 2008 como síntoma de una crisis sistémica que exigía el repensamiento radical de la institucionalidad a partir de nuevos imaginarios políticos (UNIVERSIDAD NÓMADA, 2008). Proyectos de autogestión como el CSA Tabacalera en Madrid (2009), auspiciado por la Dirección General de Bellas Artes bajo Ángeles Albert y, sobre todo, la Casa Invisible de Málaga (2007) en permanente riesgo de desalojo por parte de su ayuntamiento, venían a demostrar en la práctica la viabilidad de un tipo distinto de gobernanza institucional basado en organizaciones asamblearias y participativas, así como de una relación ecosistémica y no extractiva con el tejido de la ciudad. En sintonía e íntimo diálogo con estos procesos de agenciamiento social se han estado desarrollando proyectos educativos y de mediación en el ámbito de los museos, ya fuera desde agentes independientes como Transductores, del que forma parte Javier Rodrigo, o desde los departamentos pedagógicos de ciertas instituciones, como el dirigido por Belen Solá en el MUSAC.

El 15 de mayo de 2011 se produce una explosión multitudinaria de protestas resultado del malestar provocado por la gestión de la crisis, pero también de una sensación generalizada de obsolescencia e inadecuación del sistema económico, institucional y político en su conjunto. El ímpetu del así llamado movimiento 15M sacudió sísmicamente los términos del debate sobre cultura e institucionalidad, sacándolo de los reducidos circuitos activistas, artísticos y museísticos en que se había

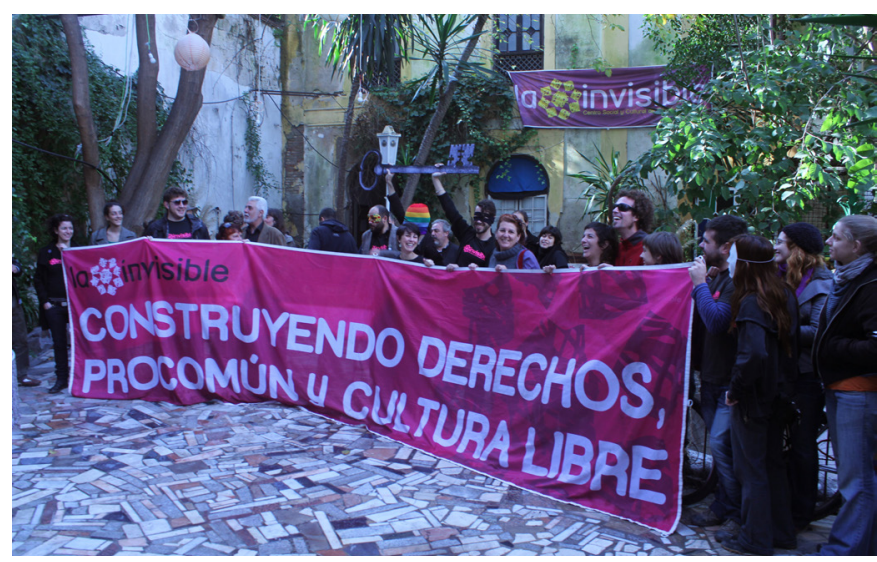

La Casa Invisible, 2011 | foto Azael_Fotos

manejado hasta entonces. Se comenzaba a hablar de democracia cultural en asambleas de barrio del mismo modo que se discutía de educación y de sanidad universales. Si bien la marea multitudinaria pronto perdería su fuerza inicial, del reflujo de la misma emergerían los así llamados "nuevos municipalismos", movimientos que pretendían llevar el agenciamiento vecinal a los consistorios, y en los que el derecho a la cultura iba a tener un rol preeminente dentro del derecho a la ciudad. Jaron Rowan explica meridianamente en su texto las dificultades estructurales que se encontró el modelo participativo vinculado a las políticas culturales de los "ayuntamientos del cambio". En este contexto y con las limitaciones derivadas de la persistencia de un aparato administrativo, organizativo y de infraestructuras concebido para otra cosa, se diseñaron y se implementaron proyectos, en su mayoría de pequeña escala, que partían de reconocer a la ciudadanía como agente de la cultura, y en los que se ensayaban protocolos de colaboración y de corresponsabilidad entre institución y tejido social (ROWAN, 2016). Dentro de este modelo cobraba protagonismo el rol del trabajador cultural, ya fuera artista, gestor, o educador, como mediador o facilitador. Más que crear, programar o enseñar, este trabajador tendría como misión el detectar, conectar y servir de correa de transmisión de las aspiraciones y potencialidades existentes en un territorio dado.

Como apuntamos al principio, la crisis de la Covid 19 ha llegado en un momento de cansancio y de escepticismo 
respecto a la posibilidad de una transformación de los dispositivos culturales independiente de una transformación profunda del aparato institucional que no se atisba en el horizonte. Pero como decíamos también, esta crisis ha puesto en evidencia la extrema fragilidad del sistema y la necesidad imperiosa de reconectar lo cultural con los principios sostenedores de la vida, en sintonía con los términos ecofeministas que ya venían enunciando voces como la de Javier Rodrigo o Yayo Herrero. En esta dirección, observamos cómo, desde distintas instancias, se ha defendido el rol "cuidador" de las instituciones culturales.

En una situación en la que nos sentimos vulnerables e invadidos por la incertidumbre, el cuidado de sí, de los otros y de nuestro entorno se vuelve una prioridad absoluta. La institución cultural, hasta ahora vinculada a las industrias de lo "accesorio": el ocio y el turismo, ha de buscar su lugar, según se nos dice, junto a las instituciones dispensadoras de lo "necesario": el hospital o la escuela. Podría interpretarse esta pretensión como la reacción a la desesperada de un museo vacío de turistas que busca su lugar en un espacio social en el que se han trastocado las prioridades. De hecho, se podría dudar de la capacidad del mundo del arte para abordar una misión de tal calado. Pablo Martínez, desde su posición de director saliente de actividades públicas del Macba, nos advierte de que la apelación a "los cuidados" podría quedarse en un giro más: etnográfico, educativo, decolonial, etc., de los que se alimenta de modo oportunista el mundo del arte, sin efecto alguno fuera de su propia enunciación (MARTÍNEZ, 2020). Al modo de la orquesta del Titanic, este sistema sería incapaz de reaccionar ante la inminencia del desastre. Siguiendo el cuento de Pedro y el lobo, las instituciones del arte habrían perdido credibilidad en la emisión de unos discursos transformadores que no tienen reflejo ni en su estructura organizativa, rígidamente jerárquica, ni en su sistema de trabajo, basado en la externalización y la precarización.

Ello es especialmente evidente, como dijimos, en las herramientas dedicadas directamente a los cuidados, como son la mediación y la educación.
Otro caveat que debería prevenirnos de asumir apresuradamente los cuidados como bandera de la nueva institución es que puede implicar un abandono de aquella carga de excepcionalidad crítica que ha reivindicado para sí tradicionalmente el arte contemporáneo, en pos de ejercer un efecto balsámico y apaciguador. En respuesta a este peligro, el director del Museo Reina Sofía, Manuel Borja-Villel (EXPÓSITO, 2020a) hace énfasis en el componente crítico y emancipador de los cuidados a los que él se refiere al imaginar el rol de la institución futura. Tal como nos recuerda el feminismo, los cuidados son políticos, "conflictuales", según apuntó durante el momento álgido de la pandemia Magdalena Fragnito en el seminario Glossary of Common Knowledge (FRAGNITO, 2020). De otra manera, serían solo caridad. Para que dicha transición hacia una verdadera "institución de los cuidados" tuviera lugar sería imprescindible la participación activa de una ciudadanía crítica. Sin esa intervención, según el activista y teórico Pantxo Ramas, tal y como ocurre en el hospital, los sujetos serían meros pacientes y la institución un vehículo de control social (RAMAS, 2020).

En conversación con el artista y activista Marcelo Expósito, Ana Longoni, directora de actividades públicas del Museo Reina Sofía, enfatizaba la urgencia de que la institución participara en la transformación de un mundo exhausto (EXPÓSITO, 2020b). Para hacerlo, recomienda que ésta revierta su hermetismo y se abra a la vitalidad y la experiencia en la lucha por la justicia de los movimientos sociales. Museo situado, una asamblea de vecinos y activistas del barrio de Lavapiés en Madrid asociada al programa de actividades públicas del Reina Sofía sería un ejemplo de cómo dicha apertura puede ser posible (CARRILLO, 2020)

Los teóricos y activistas Marco Baravalle y Emanuelle Braga, miembros históricos del movimiento autogestionario italiano, nos hablaban recientemente desde el Institute of Radical Imagination de la urgente necesidad de un cambio de paradigma que va más allá de la mera institución cultural para remitir al modelo de ciudad. Siguiendo sus argumentos, deberíamos pasar de aquella "ciudad creativa", atractiva para las operaciones 
a debate Hacia una nueva institucionalidad cultural. Modelos emergentes de gestión...

| coordina Jesús Carrillo Castillo

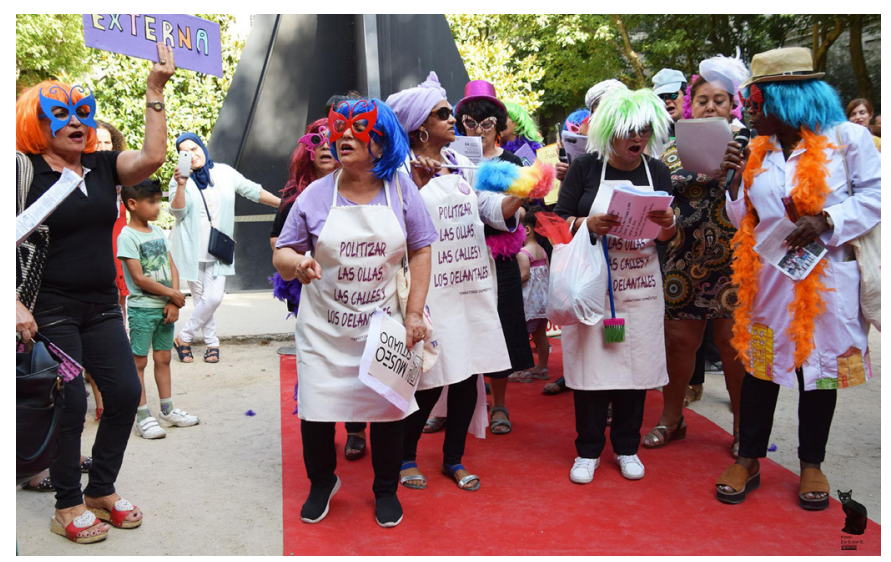

Picnic del barrio, una de las primeras iniciativas propuestas por la asamblea de la red Museo Situado. Jardín del Museo Reina Sofía, 2019 | foto Ela Rabasco (Ela R que R)

especulativas del capitalismo financiero, pero extractiva de la energía social y letal para su habitabilidad, a una "ciudad de los cuidados", que ponga en el centro el sostenimiento de la vida, de la vida de todos y de toda vida, según se desprende de su perspectiva ecofeminista. Ello dotaría a la institución cultural de un nuevo rol hacia dentro de la ciudad y hacia sus habitantes, y dejaría de ser una prolongación de la terminal del aeropuerto para el tránsito de artistas, comisarios y turistas en movimiento permanente por el circuito internacional (BRAGA, E.; BARAVALLE, M.; GAGLIANÒ, P. et ál., 2020).

Un pilar clave de esa "ciudad de los cuidados" es, para los activistas italianos, la renta básica universal e incondicional, una vieja reivindicación de los movimientos sociales que ha cobrado una nueva vigencia durante la pandemia; un momento en que se han tambaleado las bases económicas del sostenimiento de una vida digna a partir del trabajo asalariado y empresarial. En plena cuarentena, la revista de cultura crítica de Barcelona, Nativa, promovió un manifiesto "De la gent que treballa en cultura, per una renda bàsica universal i incondicional" (MURGA, 2020). En un mes la propuesta recibió casi cinco mil adhesiones de parte de artistas, colectivos, gestores, técnicos, educadores y académicos, con el fin de hacer presión a los poderes públicos. Según reza el encabezamiento del manifiesto, tal renta "sería la mejor política cultural posible". En un giro inesperado, los agentes culturales no reivindican un tratamiento excepcional debido a la especificidad del trabajo creativo, siguiendo el sistema francés, sino que vinculan íntimamente el sostenimiento de la cultura al sostenimiento general de la vida. Sus argumentos no vienen del género utópico, sino muy al contrario, de una serie de razonamientos claros acerca del modo en que tal media resolvería de un plumazo los males que aquejan a la cultura, junto con aquellos que dificultan el desarrollo de una vida digna:

"Decimos que la renta básica universal sería la mejor política cultural, porque somos conscientes de que la cultura no se construye ni se sostiene, sólo, desde el trabajo de las personas que se dedican a ella, sino que depende en todos sus aspectos de un espectro social que incluye los que habitualmente llamamos público. ¿De qué nos serviría un sistema cultural que sólo estuviera al servicio de aquellos que tienen el tiempo, los recursos y la tranquilidad para 'consumir cultura'? No tenemos más remedio que entendernos interdependientes y preocuparnos por las condiciones de vida de todo el mundo. Si la vida social no está garantizada, la cultura no es viable o acaba siendo un recurso insolidario y elitista" (NATIVA, 2020).

Más allá de este inaudito órdago de un sector de los trabajadores de la cultura, que dejan de concebir el objeto de sus esfuerzos como un accesorio de lujo, para identificarlo como un común, encontramos a partir de la situación generada por la Covid una creciente preocupación por las condiciones materiales de la cultura y un agudo malestar por el desajuste de los dispositivos institucionales y de las políticas diseñadas para el sostenimiento de tales condiciones. En ese sentido, se percibe una nueva ola de asociacionismo profesional que ya no se constituye exclusivamente en defensa de intereses corporativos, ni como lobby ante la administración, sino que pone sobre la mesa la necesidad de revertir un modelo en el que la cultura es generada mayoritariamente por unos sujetos desempoderados, altamente precarizados y que apenas recogen las migajas de unos recursos vertical y burocráticamente distribuidos. La pujante aparición durante la cuarentena de la REACC, Red de espacios y 
agentes de cultura comunitaria, viene a visibilizar un rico tejido erróneamente denominado independiente, pues depende totalmente de subvenciones y ayudas y cumple funciones sociales que deberían formar parte de la misión de las instituciones culturales públicas. Su vertebración como red tiene como fin el reivindicar una distribución justa de los recursos entre los agentes culturales, no solo para dignificar su vida, sino también las de las comunidades con las que trabajan.

La crisis de la Covid 19 ha servido para ponernos ante el espejo una institución cultural con los pies de barro, pero poseedora de una caja de herramientas conceptuales y de experiencia que deberían servir para salir reforzada y dispuesta a desplegar su esencial misión dentro de la sociedad.

\section{BIBLIOGRAFÍA}

- BLANCO, P.; CARRILLO, J.; CLARAMONTE, J. (ed.) (2001) Modos de hacer. Arte, espacio público y acción directa. Salamanca: Universidad de Salamanca, 2001

- BRAga, E.; BARAVAlle, M.; GAGLIANÒ, P.; THE INSTITUTE OF RADICAL IMAGINATION; CRISPIAN, G. (2020) A city that cares. From the creative city to the caring city, proposal for a new relational paradigm. Nero [en línea], 10 de julio de $2020<$ neroeditions.com/a-city-that-cares/> [Consulta: $14 / 09 / 20]$

- CARRILlo, J. (2008) Las nuevas fábricas de la cultura. Los lugares de la creación y la producción en la España contemporánea. En LÓPEZ CUENCA, A.; RAMÍREZPEDRAJO, E. (coord.) Propiedad intelectual, nuevas tecnologías y libre acceso a la cultura. Ciudad de México: Centro Cultural de España en México/Universidad de las Américas, 2008, pp. 281-306

- CARRILLO, J. (2018) Space invaders. intervenciones artístico-políticas en un territorio en disputa: Lavapiés (19972004). Madrid: Brumaria, 2018

- CARRILlo, J. (2020) Museo situado. Seminario The Glossary of Common Knowledge. Museo Reina Sofía, 23 de junio $2020<$ https://www.museoreinasofia.es/actividades/ glosario-conocimiento-comun> [Consulta: 14/09/20]

- EXPÓSITO, M. (2020a) Conversación con Manuel BorjaVillel, director del MNCARS. "El museo tendrá que cuidar como un hospital sin dejar de ser crítico". ctxt, Contexto y acción [en línea], 14 de mayo 2020 <https://ctxt.es/es/20200501/
Culturas/32247/Marcelo-Exposito-Manuel-Borja-Villel-museoReina-Sofia-MNCARS.htm> [Consulta: 14/09/20]

- EXPÓSITO, M. (2020b) Entrevista con Ana Longoni, escritora argentina: : "Debemos darle vuelta a este mundo desgastado que no queremos volver a habitar". Nodal, noticias de Amércia Latina y El Caribe [en línea], 5 de junio de $2020<$ https://www.nodal.am/2020/06/ana-longoni-escritoraargentina-debemos-darle-vuelta-a-este-mundo-desgastadoque-no-queremos-volver-a-habitar/> [Consulta: 14/09/20]

- FLORIDA, R. (2002) The rise of the creative class. Nueva York: Basic Books, 2002

- FRAGNito, M. (2020) Conflictual care. Seminario The Glossary of Common Knowledge. Museo Reina Sofía, 23 de junio $2020<$ https://www.museoreinasofia.es/actividades/ glosario-conocimiento-comun> [Consulta: 14/09/20]

- MARTíneZ, P. (2020) Notas para un museo por venir. ctxt, Contexto y acción [en línea], 22 junio 2020 <https://ctxt.es/ es/20200501/Culturas/32354/Pablo-Martinez-arte-ministeriopandemia-covid-19-centros-de-arte-ecologismo-queer.htm> [Consulta: 14/09/20]

- MURGA (LA) (2020) Gent que treballa en cultura, per una renda bàsica universal i incondicional. Nativa [en línea], 30 de abril de 2020, <https://nativa.cat/2020/04/gent-que-treballaen-cultura-per-una-renda-basica-universal-i-incondicional/> [Consulta: 14/09/20]

- OBSERVATORIO METROPOLITANO (ed.) (2007) Madrid ¿la suma de todos? Globalización, territorio, desigualdad. Madrid: Traficantes de sueños, 2007

- RAMAS, P. (2020) Cuidar la democracia. L'Internationales online (opinions) [en línea] <https://www.internationaleonline. org/opinions/1035_cuidar_la_democracia/> 14/09/20]

[Consulta:

- RiBAltA, J. (ed.) (1998) Servicio público. Conversaciones sobre financiación pública y arte contemporáneo. Salamanca: Universidad de Salamanca, 1998

- Rowan, J. (2016) Cultura libre de estado. Madrid: Traficantes de sueños, 2016

- UNIVERSIDAD NÓMADA (ed.) (2008) Monster institutions. Transversal texts [en línea], mayo de $2008<$ https://transversal. at/transversal/0508> [Consulta: 14/09/20]

- VILLAESPESA, M. (1989) Síndrome de mayoría absoluta. Arena Internacional del Arte, n. ${ }^{\circ} 1,1989$, pp. 82-83

- YPRODUCTIONS (ed.) (2007) Producta50. Una introducción a algunas de las relaciones que se dan entre la cultura y la economía. Barcelona: Yproductions Eds., 2007

- YúdICE, G. (2002) El recurso de la cultura. Usos de la cultura en la era global. Barcelona: Gedisa, 2002 